\title{
Current Epidemiology of Periampullary Malignancies in a Tertiary Referral Center in the Philippines: A Five-Year Review
}

\author{
Juan Carlos R. Abon, MD and A'Ericson B. Berberabe, MD \\ Division of Hepatobiliary and Pancreatic Surgery, Department of Surgery, Philippine General Hospital, University of the Philippines Manila
}

\begin{abstract}
Background. Periampullary malignancies traditionally occur during the later decades of life, but casual observations at the Philippine General Hospital (PGH) have shown more patients presenting at younger ages. Updates on the epidemiology and clinical features of these uncommon cancers may improve detection and result in better outcomes.
\end{abstract}

Objective. The study aimed to describe the current epidemiology of adult patients diagnosed with periampullary malignancies seen in the past five years at the PGH Department of Surgery.

Methods. Demographic and clinical data were obtained on patients with either pancreatic head, ampullary, distal bile duct, or duodenal cancer diagnosed from 2015 to 2019. Age and sex distributions, rates of symptom presentation, utilization of diagnostic modalities, and prevalence of comorbid conditions were analyzed per individual primary site and for the entire study population.

Results. Two hundred seventy-seven patients were included in the study, comprised mostly of pancreatic head cancers (56.32\%) followed by ampullary (19.86\%), duodenal (9.75\%), and distal CBD cancers (7.58\%). The mean age of presentation was 59.30 years. $33.94 \%$ of cases occurred in the $6^{\text {th }}$ decade of life, while $24.91 \%$ of patients were aged 50 years and below. There was a nearly equal distribution by sex (50.90\% female, $49.10 \%$ male). Majority of patients presented with jaundice (89.65\%) and abdominal pain (71.64\%). CT scan was used to diagnose $71.48 \%$ of patients. We observed a higher prevalence of diabetes mellitus (21.32\%), biliary stone disease (19.12\%), and smoking history $(36.88 \%)$ in the study group compared to the general Philippine population.

Conclusion. The epidemiology of periampullary malignancies at UP-PGH showed a younger age at presentation and an equal sex ratio compared to published data. Distributions of the primary sites, symptom frequency, and rate of associated comorbidities were consistent with previous findings from the literature.

Keywords: periampullary, epidemiology, PGH, symptoms, comorbidities

\section{INTRODUCTION}

Periampullary malignancies are not as common as cancers such as breast, lung, and colorectal. Still, they represent a significant percentage of cancer mortalities due to their inherent aggressiveness and low resection and cure rates. Statistics from the GLOBOCAN 2018 database reported a combined incidence of 678,338 new pancreatic and extrahepatic bile duct cancer cases worldwide, with 597,329

Corresponding author: Juan Carlos R. Abon, MD Division of Hepatobiliary and Pancreatic Surgery Department of Surgery

Philippine General Hospital University of the Philippines Manila Taft Avenue, Ermita, Manila 1000, Philippines Email: carlos.abon@yahoo.com deaths attributable to these cancers, irrespective of the specific location within these organs. In the Philippines, pancreatic cancer ranked $13^{\text {th }}(3,123$ new cases, representing $2.2 \%$ of all new cancer diagnoses), and bile duct cancer ranked $22^{\text {nd }}(894$ new cases, $0.63 \%$ ) in estimated local incidence in 2018. The local mortality ranks were $9^{\text {th }}$ for pancreatic cancer $(3,051$ 
deaths, representing $3.5 \%$ of all cancer mortalities) and $19^{\text {th }}$ for bile duct cancer (766 deaths, $0.89 \%){ }^{1}$

The age demographic of more common cancers has shifted towards younger patients at onset in recent years. The incidence of colorectal cancer in people younger than 50 years has increased over the past few decades in the United States, currently estimated at $12 \%$ of patients diagnosed in $2020{ }^{2}$ The same trend was seen in the Philippines, where patients diagnosed with colorectal cancer less than 40 years of age comprised 17 to $24 \% .{ }^{3}$ Patients diagnosed with breast cancer between 20 and 39 years old have also been shown to increase in the American population from 24.6 per 100,000 in 1975 to 31.7 per 100,000 in $2015 .{ }^{4}$ In the younger population, cancers are more likely to be diagnosed at a later stage. They tend to have more aggressive behavior, highlighting the significance of recognizing these shifting trends.

The relatively higher mortality rates of periampullary malignancies despite lower disease burden warrant a thorough understanding of the epidemiology and development of these cancers, including demographic-specific incidence rates and risk factors predisposing to their occurrence, to identify at-risk groups and facilitate early diagnosis and timely management. Like most other cancers, the development of periampullary malignancies has traditionally increased with advancing age, with a peak incidence at the sixth to seventh decades of life..$^{5-8}$

As a university hospital and the leading tertiary referral center in the country, the University of the Philippines - Philippine General Hospital (UP-PGH) receives many patients with presumptive or proven diagnoses of periampullary malignancies. It was observed that several cases of periampullary malignancies were diagnosed at ages younger than expected, given the currently known epidemiology of these cancers. An updated review of the current local demographics and epidemiologic data of patients with periampullary cancers and the factors associated with their development may help predict the changing trends in the incidence of these malignancies. This will play a critical role in directing and supporting future disease prevention, diagnosis, and management.

\section{General Objective}

The study aimed to describe the current epidemiology of adult patients diagnosed with periampullary malignancies seen at the Division of Hepatobiliary and Pancreatic Surgery of UP-PGH in the past five years.

\section{Specific Objectives}

Specifically, this study aimed to:

- Determine the current proportion of primary cancers arising from each of the four distinct anatomic sites under the category of periampullary malignancies;

- Define the age- and sex-related distribution of patients diagnosed with periampullary malignancies as a group entity and for each of the primary anatomic sites;
- Compare current data with previously established information on the epidemiology of periampullary malignancies;

- Describe the current symptomatology and clinical presentation of patients with periampullary malignancies; and

- Describe the current proportion of diagnostic modalities through which periampullary malignancies are detected or confirmed.

\section{METHODS}

\section{Study Design and Setting}

The study included adult patients diagnosed with one of the four types of periampullary malignancy (pancreatic head, distal bile duct, ampullary, or duodenal cancer) from January 1,2015 , to December 31, 2019. The study was a retrospective descriptive study involving a review of medical records. Convenience sampling was done, where all patients who fulfilled the inclusion criteria were included. As a tertiary referral center, the PGH was the selected study site. A high patient population that fulfilled the inclusion criteria was available due to the ready access to patients' medical records needed for recruitment and data collection.

\section{Inclusion Criteria}

Included in the study were adult patients admitted under the Department of Surgery, PGH during the period of January 1, 2015, to December 31, 2019, with a diagnosis of either pancreatic head, distal bile duct, ampullary, or duodenal carcinoma based on preoperative imaging and work-up, or those with the same diagnoses after surgical resection and histopathologic examination, whose medical records were available. Patients admitted under both the service and private arms of the hospital were included. Patients who had either undergone resective surgery, received palliative surgery or had non-operative management were also included.

\section{Exclusion Criteria}

Excluded from the study were patients whose imaging studies or surgery could not prove the diagnosis of periampullary malignancy, whose further diagnostics or surgical exploration revealed a final diagnosis other than periampullary malignancy, and whose medical records were unavailable for retrieval.

\section{Data Collection}

Patients who qualified for inclusion in the study were identified using the diagnosis query function of the Integrated Surgical Information System (ISIS) of the Department of Surgery using the keywords 'periampullary', 'pancreatic head,' 'cholangiocarcinoma,' 'distal CBD,' 'distal common bile duct,' 'ampullary,' 'duodenal,' 'mass,' 'tumor,' 'cancer,' and 'carcinoma' for the period of January 1, 2015, to December 31, 2019. The medical records of the potential study subjects were retrieved 
from the UP-PGH Medical Records Division. Based on diagnostic imaging or histopathology, these were further reviewed to identify which patients fulfilled the inclusion criteria for recruitment.

The principal investigator performed the data collection. Information on cancer classification and presentation and data on both modifiable and non-modifiable risk factors known to impact the development of periampullary malignancies were collected. These included demographic information such as age and sex; primary site of malignancy based on preoperative diagnostics, intraoperative assessment, or post-operative histopathology; symptoms on presentation; and conditions such as increased body mass index (BMI), the incidence of other malignancies, diabetes mellitus (DM), biliary disorders, history of tobacco use, and other comorbid diseases. All clinical information obtained from the medical records was recorded using a standard data collection form.

\section{Data Management}

Data was encoded in a digital spreadsheet and summarized in a table format. Data analysis was performed using the Epi Info version 7.2.4.0 statistical analysis software from the Centers for Disease Control and Prevention website. Graphs were generated using Microsoft Excel.

Patient age was expressed as mean values with standard deviations and discrete counts and percentages per decade of life. Discrete variables such as sex, presenting symptoms, and various risk factors were tabulated as counts and percentage rates. The distribution of each primary site was expressed as percentages of the total incidence of periampullary malignancies. Other missing variables were not replaced nor estimated. The mean age of incidence and the distribution of incidence between age groups and sexes for the different types of periampullary malignancies were determined and compared. Their concordance to classic knowledge about the demographics of periampullary malignancies was defined and assessed. From the data collected, we decided the distribution and percentages of presenting symptoms, the presence of comorbid conditions, and the modalities used to diagnose the different cancer primary sites.

\section{RESULTS}

Seven hundred sixty-one potential patients were initially identified for inclusion over the five years from January 2015 to December 2019. Of these, 366 had retrievable medical records, and 89 patients were excluded based on a review of the charts. Two hundred seventy-seven patients were included in the study and had their clinical information collected for data analysis.

The primary anatomic origin of the periampullary malignancies of the study subjects was determined based on the available diagnostic imaging results, intraoperative findings, and histopathology reports (Table 1). Pancreatic head malignancies comprised most of the population, with $56.32 \%$ of patients (156 out of 277). This is followed by 55 ampullary malignancies comprising 19.86\%, 27 duodenal cancers making up $9.75 \%$ of the population, and 21 malignancies arising from the distal common bile duct, representing $7.58 \%$. Eighteen patients $(6.50 \%$ of the study population) did not have a specific anatomic site identified as the origin of their malignancy based on the diagnostic tests performed and did not undergo an operation.

Age and sex distributions were obtained for the entire study population and divided per primary site (Table 2). The average age of patients with periampullary malignancies included in the study is 59.30 years, with each primary site having similar mean ages. There was an almost equal distribution of patients between sex, with $50.90 \%$ female and $49.10 \%$ male. Nearly equal division by sex was also seen when looking at the patients grouped by primary site.

The incidence of malignancy per decade of life for each primary site and the entire study population is tabulated in Table 3. Peak incidence was seen in the $5^{\text {th }}$ and $6^{\text {th }}$ decades of life, making up $24.19 \%$ and $33.94 \%$ of overall cases, respectively. Incidence increased as age progressed until it
Table 1. Distribution by primary site

\begin{tabular}{lc}
\multicolumn{1}{c}{ Primary Site } & Number (\%) \\
Pancreatic head & $156(56.32 \%)$ \\
Ampulla & $55(19.86 \%)$ \\
Duodenum & $27(9.75 \%)$ \\
Distal CBD & $21(7.58 \%)$ \\
Not specified & $18(6.50 \%)$ \\
Overall & $277(100 \%)$ \\
\hline
\end{tabular}

Table 2. Demographics by primary site

\begin{tabular}{|c|c|c|c|}
\hline \multirow{2}{*}{ Primary Site } & \multirow{2}{*}{$\begin{array}{c}\text { Age in years (SD) } \\
\text { Range }\end{array}$} & \multicolumn{2}{|c|}{ Sex } \\
\hline & & Female & Male \\
\hline Pancreatic head ( $n=156)$ & $\begin{array}{l}58.92(12.06) \\
\text { Range: } 31-89\end{array}$ & $80(51.28 \%)$ & $76(48.72 \%)$ \\
\hline Ampulla ( $n=55)$ & $\begin{array}{l}61.09(10.48) \\
\text { Range: } 37-84\end{array}$ & 27 (49.09\%) & 28 (50.91\%) \\
\hline Duodenum ( $n=27)$ & $\begin{array}{l}58.59(10.80) \\
\text { Range: } 37-78\end{array}$ & $14(51.85 \%)$ & $13(48.15 \%)$ \\
\hline Distal CBD ( $n=21)$ & $\begin{array}{l}57.86(14.20) \\
\text { Range: } 19-78\end{array}$ & $10(47.62 \%)$ & 11 (52.38\%) \\
\hline Not specified $(n=18)$ & $\begin{array}{l}59.89 \text { (17.29) } \\
\text { Range: } 27-83\end{array}$ & $10(55.56 \%)$ & 8 (44.44\%) \\
\hline Overall $(n=277)$ & $\begin{array}{l}59.30 \text { (12.17) } \\
\text { Range: 19-89 }\end{array}$ & $141(50.90 \%)$ & $136(49.10 \%)$ \\
\hline
\end{tabular}


Table 3. Distribution by age group per primary site

\begin{tabular}{|c|c|c|c|c|c|c|c|}
\hline \multirow{4}{*}{$\begin{array}{l}\text { Pancreatic head } \\
(n=156)\end{array}$} & $\leq 30$ & $31-40$ & $41-50$ & $51-60$ & $61-70$ & $71-80$ & $>80$ \\
\hline & \multicolumn{3}{|c|}{50 below } & \multicolumn{4}{|c|}{ Above 50} \\
\hline & 0 & 13 (8.33\%) & 27 (17.31\%) & 39 (25.00\%) & 52 (33.33\%) & 20 (12.82\%) & 5 (3.21\%) \\
\hline & \multicolumn{3}{|c|}{40 (25.64\%) } & \multicolumn{4}{|c|}{$116(74.36 \%)$} \\
\hline \multirow{2}{*}{$\begin{array}{l}\text { Ampulla } \\
(n=55)\end{array}$} & 0 & 2 (3.64\%) & $9(16.36 \%)$ & $13(23.64 \%)$ & $20(36.36 \%)$ & 10 (18.18\%) & 1 (1.82\%) \\
\hline & \multicolumn{3}{|c|}{$11(20 \%)$} & \multicolumn{4}{|c|}{44 (80\%) } \\
\hline \multirow{2}{*}{$\begin{array}{l}\text { Duodenum } \\
(n=27)\end{array}$} & 0 & $2(7.41 \%)$ & $5(18.52 \%)$ & 7 (25.93\%) & 11 (40.74\%) & $2(7.41 \%)$ & 0 \\
\hline & \multicolumn{3}{|c|}{7 (25.93\%) } & \multicolumn{4}{|c|}{20 (74.07\%) } \\
\hline \multirow{2}{*}{$\begin{array}{l}\text { Distal CBD } \\
(n=21)\end{array}$} & 2 (9.52\%) & 0 & 3 (14.29\%) & $6(28.57 \%)$ & $6(28.57 \%)$ & $4(19.05 \%)$ & 0 \\
\hline & \multicolumn{3}{|c|}{$5(23.81 \%)$} & \multicolumn{4}{|c|}{$16(76.19 \%)$} \\
\hline \multirow{2}{*}{$\begin{array}{l}\text { Not specified } \\
(n=18)\end{array}$} & $1(5.56 \%)$ & $1(5.56 \%)$ & $4(22.22 \%)$ & 2 (11.11\%) & 5 (27.78\%) & 3 (16.67\%) & 2 (11.11\%) \\
\hline & \multicolumn{3}{|c|}{6 (33.33\%) } & \multicolumn{4}{|c|}{12 (66.67\%) } \\
\hline \multirow{2}{*}{$\begin{array}{l}\text { Overall } \\
(n=277)\end{array}$} & 3 (1.08\%) & 18 (6.50\%) & 48 (17.33\%) & 67 (24.19\%) & 94 (33.94\%) & 39 (14.08\%) & $8(2.89 \%)$ \\
\hline & \multicolumn{3}{|c|}{69 (24.91\%) } & \multicolumn{4}{|c|}{208 (75.09\%) } \\
\hline
\end{tabular}

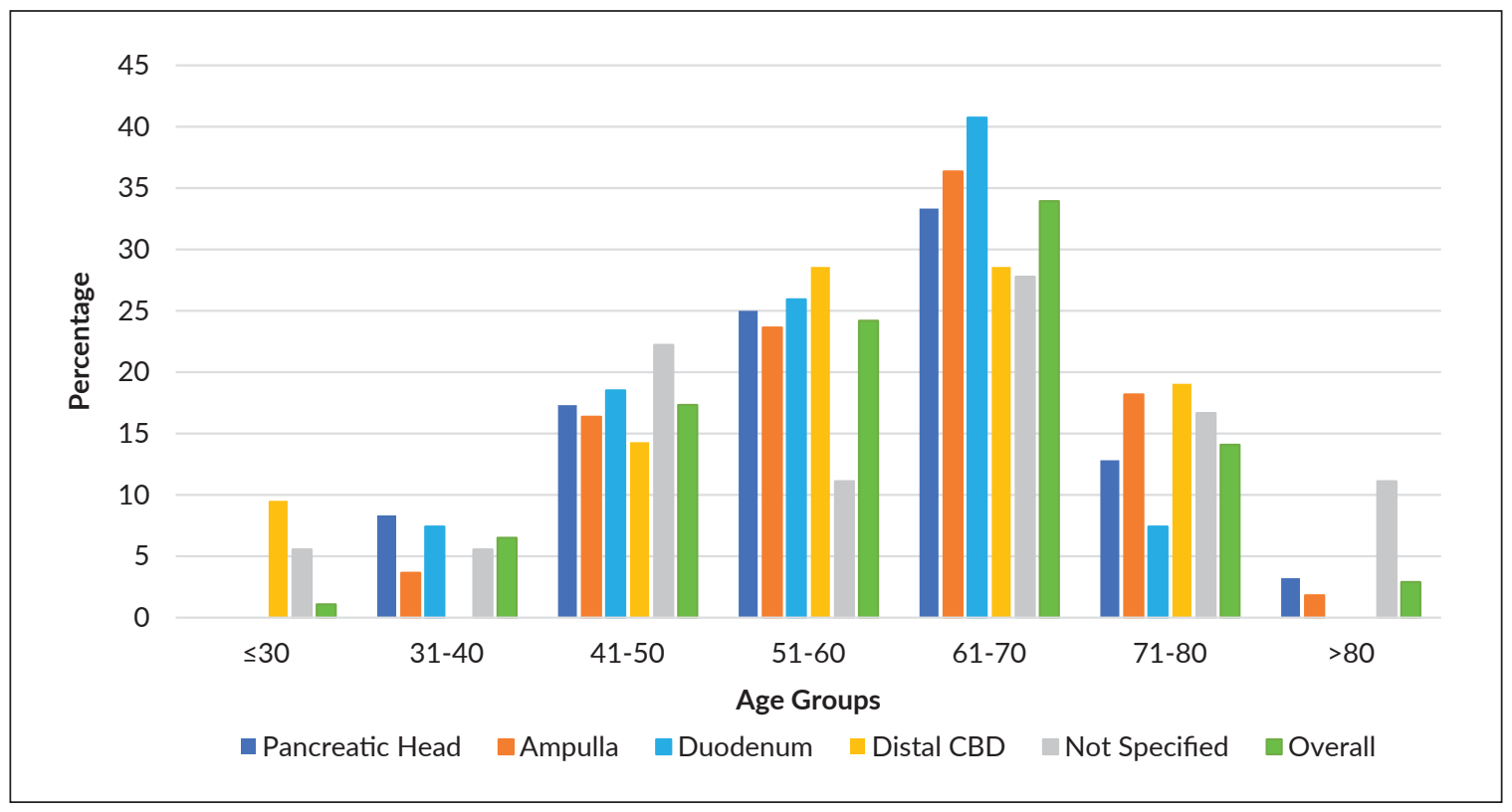

Figure 1. Age group comparison between primary sites.

peaked at the $6^{\text {th }}$ decade, after which it decreased with further advancing age. The same pattern was mainly followed for all four different primary sites. A deviation from the overall trend was seen in the $\leq 30$ groups for primary malignancies from the distal common bile duct, wherein 2 out of 3 cases in this age bracket were seen to arise from the distal CBD comprising $9.52 \%$ of all distal CBD malignancy cases. No patients from the other anatomic sites were seen in this age group. Dividing the population into broad groups of early- or regular-onset cancers, $24.91 \%$ of all patients were 50 years and below upon disease diagnosis, while the majority at $75.09 \%$ were above 50 years of age. Similar ratios were observed among the subgroups by primary site. The percentage trends in Figure 1 illustrates these findings.
The frequency of symptoms reported by the patients in the study is summarized in Table 4 . The most common symptom noted was jaundice, which was present in $89.45 \%$ of all study patients. This was followed by abdominal pain of any severity or character (71.64\%), tea-colored urine (56\%), weight loss (46.55\%), acholic stools (32.73\%), and pruritus (26.91\%). The least common symptoms seen throughout the entire study population were fever (19.71\%), nausea and vomiting (18.55\%), and gastrointestinal bleeding usually manifesting as melena or hematemesis (12\%).

Looking at the manner of presentation by primary site, the overall trend was followed, generally, by lesions arising from the pancreatic head, distal CBD, and ampulla. For patients with tumors of duodenal origin, there was a decreased percentage of patients presenting with jaundice, 
Table 4. Presenting symptoms by primary site

\begin{tabular}{|c|c|c|c|c|c|c|c|c|c|}
\hline & Jaundice & $\begin{array}{l}\text { Abdominal } \\
\text { pain }\end{array}$ & $\begin{array}{l}\text { Tea-colored } \\
\text { urine }\end{array}$ & Weight loss & $\begin{array}{l}\text { Acholic } \\
\text { stools }\end{array}$ & Pruritus & Fever & $\begin{array}{l}\text { Nausea/ } \\
\text { vomiting }\end{array}$ & GI bleeding \\
\hline $\begin{array}{l}\text { Pancreatic head } \\
(n=156)\end{array}$ & $\begin{array}{c}141 \\
(90.38 \%)\end{array}$ & $\begin{array}{c}113 \\
(72.44 \%)\end{array}$ & $\begin{array}{c}88 \\
(56.41 \%)\end{array}$ & $\begin{array}{c}70 \\
(44.87 \%)\end{array}$ & $\begin{array}{c}58 \\
(37.18)\end{array}$ & $\begin{array}{c}43 \\
(27.56 \%)\end{array}$ & $\begin{array}{c}25 \\
(16.03 \%)\end{array}$ & $\begin{array}{c}28 \\
(17.95 \%)\end{array}$ & $\begin{array}{c}13 \\
(8.33 \%)\end{array}$ \\
\hline $\begin{array}{l}\text { Ampulla } \\
(n=55)\end{array}$ & $\begin{array}{c}52 \\
(94.55 \%) \\
\end{array}$ & $\begin{array}{c}33 \\
(60.00 \%) \\
\end{array}$ & $\begin{array}{c}31 \\
(56.36 \%) \\
\end{array}$ & $\begin{array}{c}23 \\
(41.82 \%) \\
\end{array}$ & $\begin{array}{c}13 \\
(23.64 \%) \\
\end{array}$ & $\begin{array}{c}18 \\
(32.73 \%) \\
\end{array}$ & $\begin{array}{c}15 \\
(27.27 \%) \\
\end{array}$ & $\begin{array}{c}9 \\
(16.36 \%) \\
\end{array}$ & $\begin{array}{c}5 \\
(9.09 \%) \\
\end{array}$ \\
\hline $\begin{array}{l}\text { Duodenum } \\
(n=27)\end{array}$ & $\begin{array}{c}16 \\
(59.26 \%)\end{array}$ & $\begin{array}{c}25 \\
(92.59 \%) \\
\end{array}$ & $\begin{array}{c}11 \\
(40.74 \%)\end{array}$ & $\begin{array}{c}15 \\
(55.56 \%) \\
\end{array}$ & $\begin{array}{c}4 \\
(14.81 \%)\end{array}$ & $\begin{array}{c}2 \\
(7.41 \%) \\
\end{array}$ & $\begin{array}{c}5 \\
(19.23 \%) \\
\end{array}$ & $\begin{array}{c}7 \\
(25.93 \%) \\
\end{array}$ & $\begin{array}{c}12 \\
(44.44 \%) \\
\end{array}$ \\
\hline $\begin{array}{l}\text { Distal CBD } \\
(n=20)\end{array}$ & $\begin{array}{c}20 \\
(100 \%) \\
\end{array}$ & $\begin{array}{c}13 \\
(65.00 \%) \\
\end{array}$ & $\begin{array}{c}13 \\
(65.00 \%) \\
\end{array}$ & $\begin{array}{c}10 \\
(50.00 \%) \\
\end{array}$ & $\begin{array}{c}11 \\
(55.00 \%) \\
\end{array}$ & $\begin{array}{c}8 \\
(40.00 \%) \\
\end{array}$ & $\begin{array}{c}3 \\
(15.00 \%) \\
\end{array}$ & $\begin{array}{c}3 \\
(15.00 \%) \\
\end{array}$ & 0 \\
\hline $\begin{array}{l}\text { Not specified } \\
(n=17)\end{array}$ & $\begin{array}{c}17 \\
(100 \%)\end{array}$ & $\begin{array}{c}13 \\
(76.47 \%)\end{array}$ & $\begin{array}{c}11 \\
(64.71 \%)\end{array}$ & $\begin{array}{c}10 \\
(58.82 \%)\end{array}$ & $\begin{array}{c}4 \\
(23.53 \%)\end{array}$ & $\begin{array}{c}3 \\
(17.65 \%)\end{array}$ & $\begin{array}{c}6 \\
(35.29 \%)\end{array}$ & $\begin{array}{c}4 \\
(23.53 \%)\end{array}$ & $\begin{array}{c}3 \\
(17.65 \%)\end{array}$ \\
\hline $\begin{array}{l}\text { Overall } \\
(n=275)\end{array}$ & $\begin{array}{c}246 \\
(89.45 \%)\end{array}$ & $\begin{array}{c}197 \\
(71.64 \%)\end{array}$ & $\begin{array}{c}154 \\
(56.00 \%)\end{array}$ & $\begin{array}{c}128 \\
(46.55 \%)\end{array}$ & $\begin{array}{c}90 \\
(32.73 \%)\end{array}$ & $\begin{array}{c}74 \\
(26.91 \%)\end{array}$ & $\begin{array}{c}54 \\
(19.71 \%)\end{array}$ & $\begin{array}{c}51 \\
(18.55 \%)\end{array}$ & $\begin{array}{c}33 \\
(12.00 \%)\end{array}$ \\
\hline
\end{tabular}

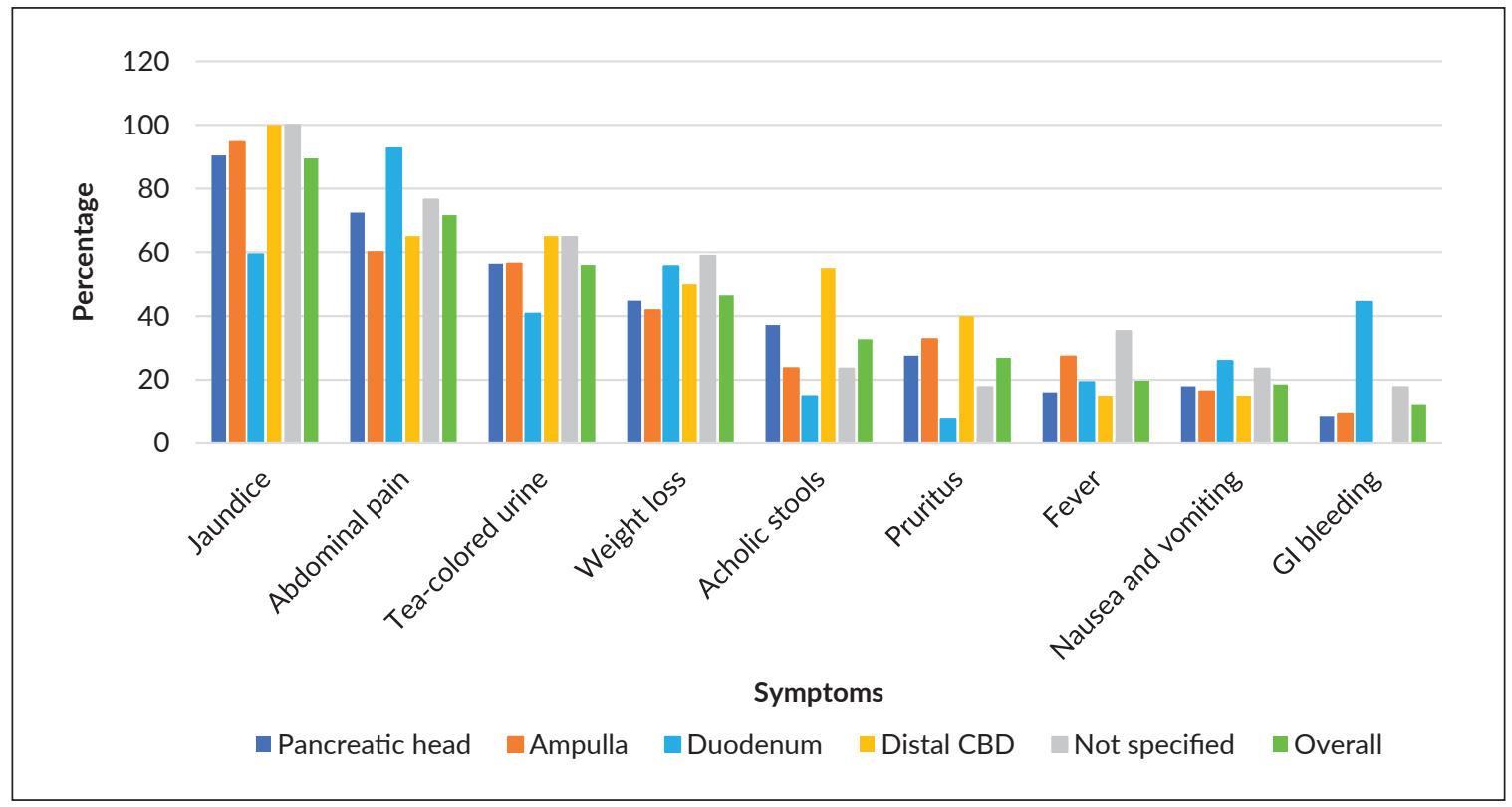

Figure 2. Symptom percentage comparison between primary sites.

tea-colored urine, acholic stools, and pruritus $(59.26 \%$, $40.74 \%, 14.81 \%$, and $7.41 \%$, respectively). In contrast, the percentage of these patients presenting with abdominal pain, nausea and vomiting, and gastrointestinal bleeding was higher (92.59\%, 25.93\%, and 44.44\%, respectively). The comparison of the percentages of patients presenting with the various symptoms among the four primary anatomic sites is illustrated in Figure 2.

The different diagnostic tools utilized in arriving at a cancer diagnosis were tallied for each patient group (Table 5). CT scans were the most frequently used (71.48\% of the cases), followed by upper GI endoscopy (28.16\%) and endoscopic ultrasound (11.55\%). MRI and intraoperative ultrasound were the least used to confirm the diagnosis of periampullary malignancy, having been employed in only $9.39 \%$ and $7.22 \%$ of the study population. It was also noted that patients in the study generally underwent several diagnostic procedures to identify their pathology. Multiple tests may have been used to arrive at a conclusive diagnosis.

Upper GI endoscopy has a higher positive test rate in ampullary or duodenal cancers, helping us arrive at a diagnosis in $69.09 \%$ and $85.19 \%$ of these cases, respectively. CT scan had a lower diagnostic utility in distal CBD tumors, helping us diagnose the disease in only $42.86 \%$ of patients. In contrast, MRI, endoscopic, and intraoperative ultrasound had higher usage rates for distal CBD cases at $19.05 \%, 18.05 \%$, and $19.05 \%$, respectively. The comparative rates of diagnostic usage among the primary sites are shown in Figure 3.

The incidence of coexisting diseases that have been shown to increase the risk of periampullary malignancies was investigated. These include BMI greater than $25 \mathrm{~kg} / \mathrm{m} 2$, diabetes mellitus (DM), a history of cancer in other primary sites, biliary stone disease, and smoking history (Table 6). Overall, $17.95 \%$ of patients were overweight or obese with a 
Table 5. Method of diagnosis by primary site

\begin{tabular}{|c|c|c|c|c|c|c|}
\hline & $\begin{array}{c}\mathrm{CT} \\
(\mathrm{n}, \%)\end{array}$ & $\begin{array}{c}\text { Upper GI endoscopy } \\
\text { (n, \%) }\end{array}$ & $\begin{array}{l}\text { Endoscopic ultrasound } \\
(\mathrm{n}, \%)\end{array}$ & $\begin{array}{l}\text { MRI } \\
(\mathrm{n}, \%)\end{array}$ & $\begin{array}{l}\text { Intraoperative } \\
\text { ultrasound }(n, \%)\end{array}$ & $\begin{array}{l}\text { None specified } \\
\text { (n, \%) }\end{array}$ \\
\hline $\begin{array}{l}\text { Pancreatic head } \\
(n=156)\end{array}$ & 126 (80.77\%) & 11 (7.05\%) & 22 (14.10\%) & 15 (9.62\%) & 11 (7.05\%) & 7 (4.49\%) \\
\hline $\begin{array}{l}\text { Ampulla } \\
(n=55)\end{array}$ & 34 (61.82\%) & 38 (69.09\%) & 6 (10.91\%) & 5 (9.09\%) & $4(7.27 \%)$ & 2 (3.64\%) \\
\hline $\begin{array}{l}\text { Duodenum } \\
(n=27)\end{array}$ & 21 (77.78\%) & 23 (85.19\%) & 0 & 1 (3.70\%) & 0 & $1(3.70 \%)$ \\
\hline $\begin{array}{l}\text { Distal CBD } \\
(n=21)\end{array}$ & $9(42.86 \%)$ & $6(28.57 \%)$ & 4 (19.05\%) & 4 (19.05\%) & 4 (19.05\%) & 2 (9.52\%) \\
\hline $\begin{array}{l}\text { Not specified } \\
(n=18)\end{array}$ & 8 (44.44\%) & 0 & 0 & $1(5.56 \%)$ & $1(5.56 \%)$ & 8 (44.44\%) \\
\hline $\begin{array}{l}\text { Overall } \\
(n=277)\end{array}$ & 198 (71.48\%) & 78 (28.16\%) & 32 (11.55\%) & $26(9.39 \%)$ & $20(7.22 \%)$ & 20 (8.30\%) \\
\hline
\end{tabular}

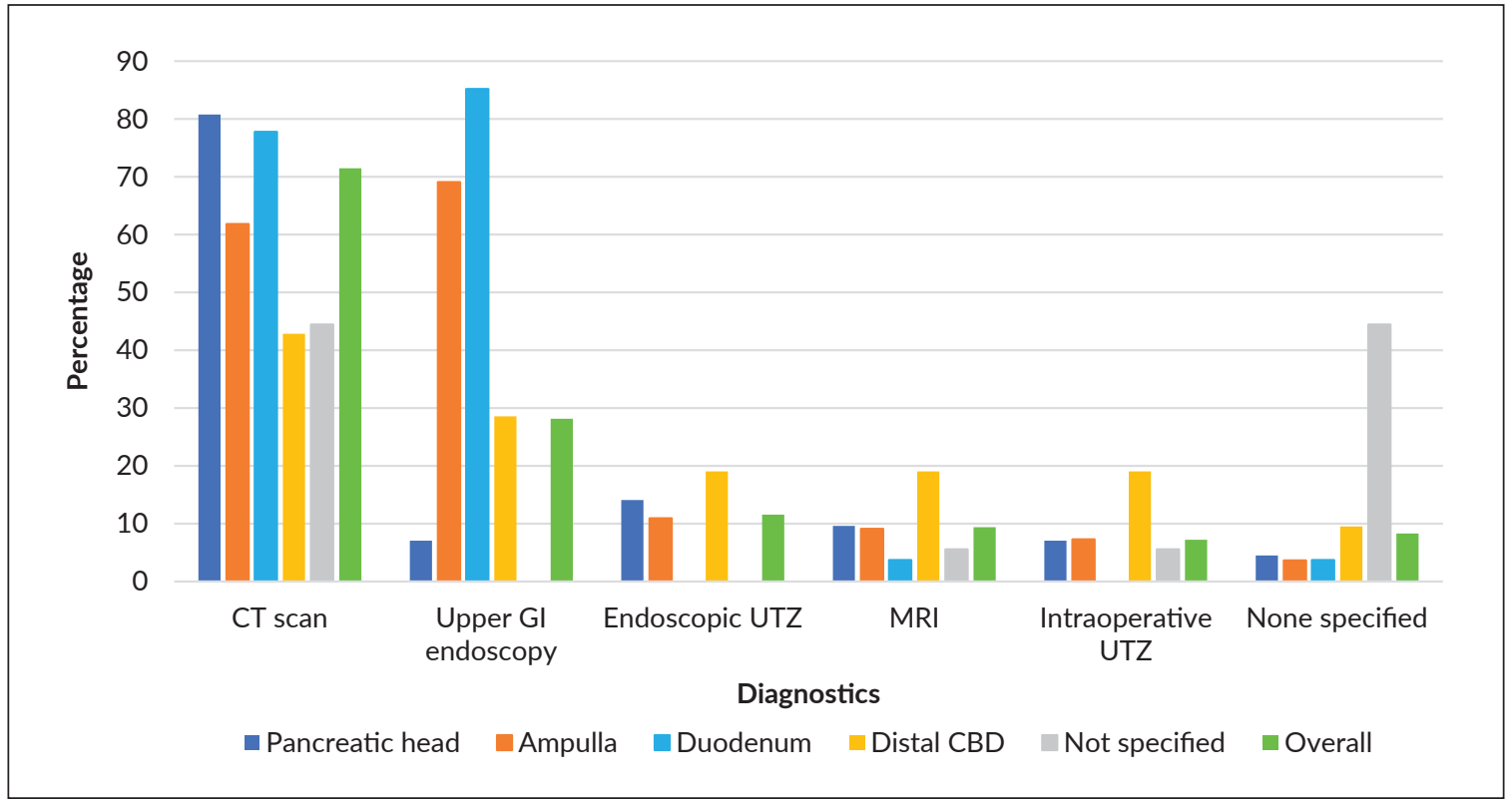

Figure 3. Comparison of diagnostics utilized between primary sites.

BMI greater than 25 , and $21.32 \%$ had type $2 \mathrm{DM}$. The biliary disease was seen in $19.12 \%$ of all the patients, the majority of which were diagnosed with cholelithiasis. 4 patients also had a history of choledocholithiasis. In contrast, one patient with a distal CBD malignancy had a childhood diagnosis of a choledochal cyst. Smoking history was prevalent in 36.88\% of the study patients. $2.94 \%$ of patients presented with a history of malignancies in other organs. Three patients with pancreatic head cancer had colon cancer, breast cancer, and an undiagnosed esophageal mass detected on endoscopy within the different patient groups. One patient with a distal CBD tumor had a history of rectal cancer. In contrast, two patients with duodenal cancers had colon cancer. Two patients with an unspecified periampullary tumor had a history of breast and nasopharyngeal cancer.

Among the four patient groups, the frequencies of the various comorbid conditions were mainly similar. The prevalence of diabetes was highest in the pancreatic head malignancy group at $25.32 \%$, while biliary disease was most significant in the distal CBD malignancy group at $28.57 \%$. A lower frequency of elevated BMI and DM was seen in the duodenal cancer group ( $7.69 \%$ and $11.54 \%$, respectively). The fraction of patients with a smoking history was considerably more significant at $64 \%$ in the same group. The comparisons of the prevalence of these comorbid conditions are shown in Figure 4.

The prevalence of the various comorbid conditions was compared between broader groups composed of patients 50 years old and below and those above 50 years of age, reflecting the increased incidence of periampullary malignancies starting at the fifth decade of life, to explore possible correlations with developing periampullary cancer at a younger age (Table 7). There was a similar prevalence of other malignancies, biliary disorders, and smoking between the two age groups. DM 
Table 6. Comorbidities by primary site

\begin{tabular}{lccccc}
\hline & BMI > 25 (n, \%) & History of other cancer (n, \%) & Diabetes mellitus (n, \%) & Biliary disease (n, \%) & Smoking (n, \%) \\
\hline Pancreatic head & $17 / 91(18.68 \%)$ & $3 / 154(1.95 \%)$ & $39 / 154(25.32 \%)$ & $25 / 154(16.23 \%)$ & $53 / 148(35.81 \%)$ \\
\hline Ampulla & $7 / 34(20.59 \%)$ & $0 / 54(0 \%)$ & $11 / 54(20.37 \%)$ & $12 / 54(22.22 \%)$ & $16 / 54(29.63 \%)$ \\
\hline Duodenum & $1 / 13(7.69 \%)$ & $2 / 26(7.69 \%)$ & $3 / 26(11.54 \%)$ & $6 / 26(23.08 \%)$ & $16 / 25(64.00 \%)$ \\
\hline Distal CBD & $3 / 14(21.43 \%)$ & $1 / 21(4.76 \%)$ & $4 / 21(19.05 \%)$ & $6 / 21(28.57 \%)$ & $6 / 19(31.58 \%)$ \\
\hline Not specified & $0 / 4(0 \%)$ & $2 / 17(11.76 \%)$ & $1 / 17(5.88 \%)$ & $3 / 17(17.65 \%)$ & $6 / 17(35.29 \%)$ \\
\hline Overall & $28 / 156(17.95 \%)$ & $8 / 272(2.94 \%)$ & $58 / 272(21.32 \%)$ & $52 / 272(19.12 \%)$ & $97 / 263(36.88 \%)$ \\
\hline
\end{tabular}

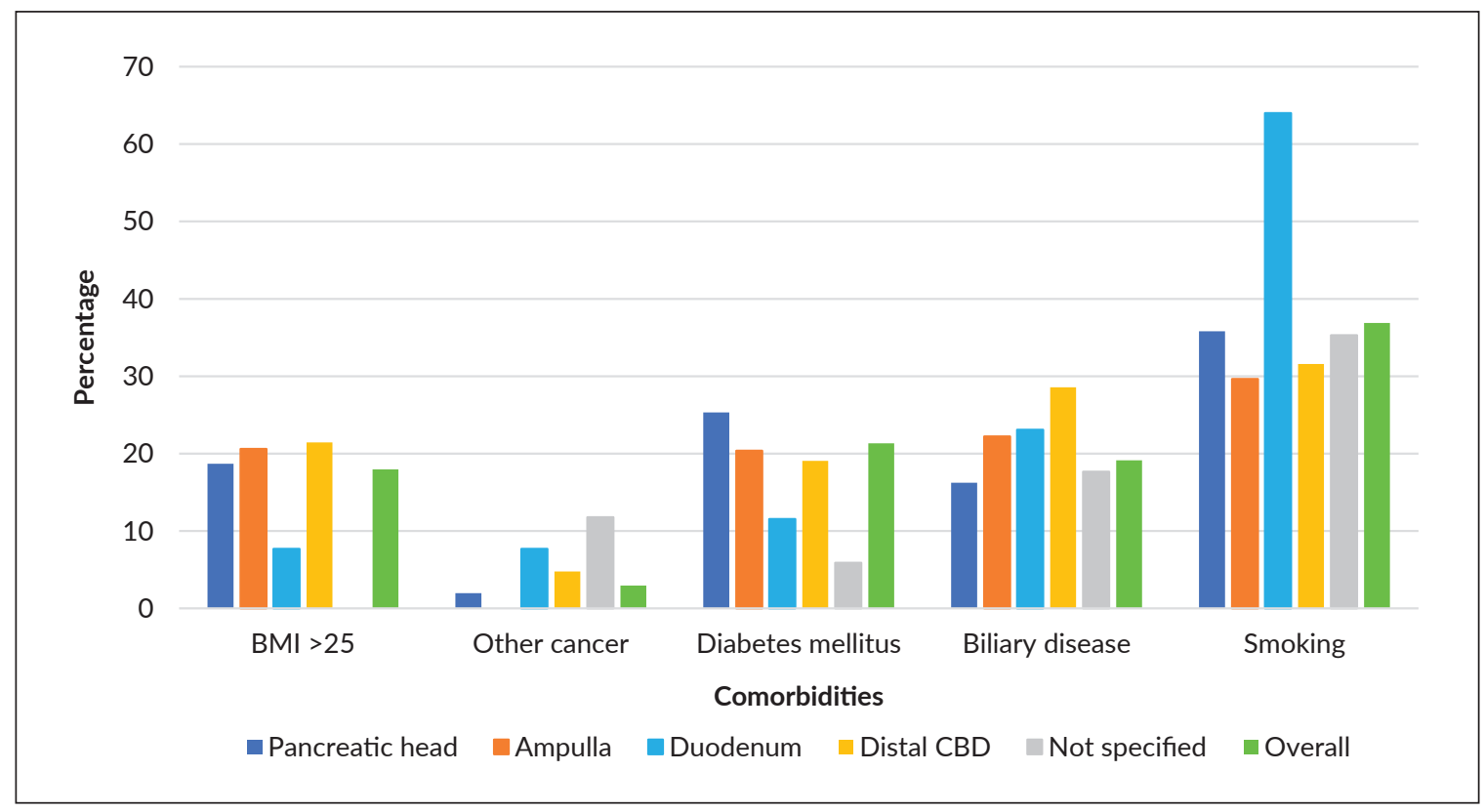

Figure 4. Comparison of incidence of comorbidities between primary sites.

Table 7. Comorbidities by age group (50 below and above 50 )

\begin{tabular}{lrrrr} 
& \multicolumn{2}{c}{50 below } & \multicolumn{2}{c}{ Above $\mathbf{5 0}$} \\
\hline BMI > 25 & $10 / 41$ & $24.39 \%$ & $18 / 115$ & $15.65 \%$ \\
History of other cancer & $3 / 69$ & $4.35 \%$ & $5 / 203$ & $2.46 \%$ \\
Diabetes mellitus & $8 / 69$ & $11.59 \%$ & $50 / 203$ & $24.63 \%$ \\
Biliary disease & $13 / 69$ & $18.84 \%$ & $39 / 203$ & $19.21 \%$ \\
Smoking & $22 / 66$ & $33.33 \%$ & $75 / 197$ & $38.07 \%$ \\
\hline
\end{tabular}

was more common in the above 50 groups, with $24.63 \%$ of patients presenting with DM than $11.59 \%$ in the 50 below. $24.39 \%$ of patients in the 50 below group had an elevated BMI greater than 25 , compared to $15.65 \%$ of patients above 50 years of age. These comparisons are illustrated in Figure 5.

\section{DISCUSSION}

The composition of periampullary malignancies is divided into pancreatic head cancers comprising 61-72\%, ampullary cancers (19-23\%), cancers of the distal CBD (5$12 \%)$, and duodenal cancers comprising around 7\%. ${ }^{9-10}$ The present study results support these figures, with pancreatic head malignancies making up over half of the population, ampullary cancer with around 20\%, and less than 10\% each for duodenal and distal CBD malignancies. Within the $\mathrm{PGH}$, the prevalence of periampullary cancers still comprises a minority of all malignancies seen, trailing behind more common cancers such as breast, colorectal, lung, gynecologic, and head, and neck. From the latest 3-year Medical Oncology census, pancreatic cancers made up $1.3 \%$ of the total cancer burden for combined inpatient and outpatient treatments. In contrast, hepatobiliary cancers comprised $1.5 \%$, and an unspecified smaller percentage would be from extrahepatic cholangiocarcinomas. ${ }^{11}$ There was no notable change in the percentage composition of pancreatic and hepatobiliary cancers in the three years covered by the report.

Previous reports have demonstrated a male predominance in all periampullary malignancies, with up to a $1.3: 1$ maleto-female ratio reported in pancreatic cancers., ${ }^{5,9,10,12-15}$ The incidence of all types of periampullary malignancies was most significant in the later decades of life. Pancreatic cancer was said to peak at the seventh and eighth decades of life, with a median age of onset of 71 years and less than $10 \%$ of cases occurring in patients less than 55 years old. ${ }^{13-15}$ Ampullary 


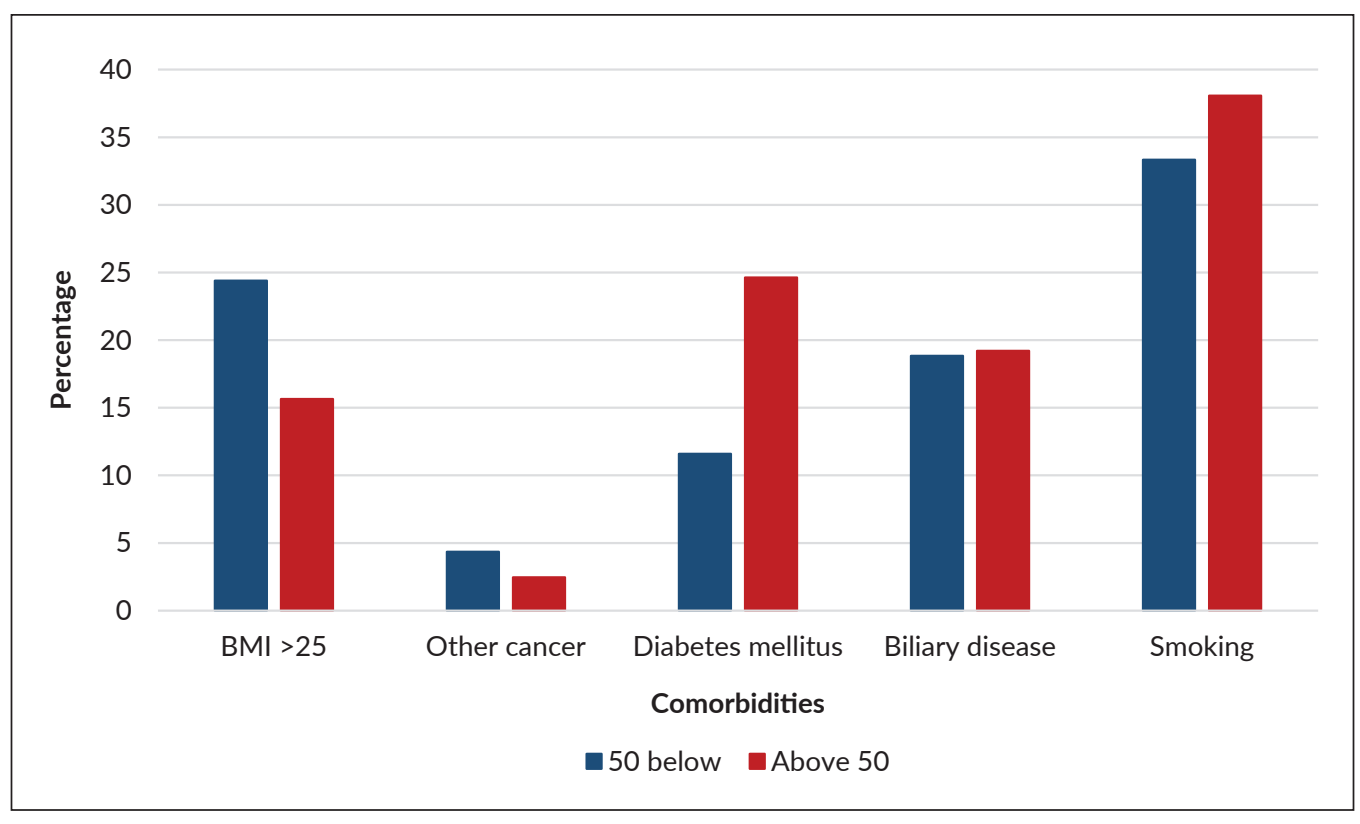

Figure 5. Comparison of comorbidities by age group.

adenocarcinoma was diagnosed at an average of 60 to 70 years of age, while small bowel adenocarcinomas presented at a mean of 68 years of age, of which $57 \%$ manifested in the duodenum. ${ }^{12,13,16,17}$ Cholangiocarcinomas were most common between the fifth to seventh decades of life, and around $40 \%$ occur within the distal extrahepatic bile duct at the periampullary region. ${ }^{7,14,18}$ Early onset of disease before 50 years of age was previously observed in 8 to $10 \%$ of patients with pancreatic cancer, the most studied among the periampullary tumor subtypes. ${ }^{19-22}$

In contrast to the previously established demographics of periampullary cancers, the current study showed a younger overall mean age. The male-to-female ratio was nearly equal within all patient groups. Based on the literature, a fourth of the study population presented with the disease before 50 years of age, which was higher than the expected percentage of patients presenting within this age group. It remains to be seen if the lower institutional incidence of periampullary malignancy in patients aged 70 and above and the higher proportion of patients below 50 years might be due to an overall lower life expectancy, or differences in access to hospital systems and health-seeking behaviors, which may be elaborated in larger population-based studies in the local setting.

Studies on early-onset pancreatic cancer have shown correlations between tobacco use and earlier incidence, implicated in up to half of cases. This was concluded from a strong association of early-onset pancreatic cancer and lung cancer and the higher male-to-female ratio in young patients due to the higher percentage of male smokers. ${ }^{19-20}$ The incidence of pancreatic cancer associated with familial cancer syndromes has been shown to have a more significant percentage of patients less than 50 years of age ( $36.7 \%$ versus
$18.3 \%$ in the sporadic cancer group). Smoking history was more common in the familial pancreatic carcinoma group (87\% versus $66 \%) .{ }^{23}$ Earlier onset of pancreatic cancer was also seen in smokers versus nonsmokers among patients with a family history of pancreatic cancer or hereditary pancreatitis, suggesting an additive effect between smoking and genetic factors. ${ }^{19}$ Despite these findings, several studies have failed to establish a conclusive causative association between genetic syndromes and early-onset pancreatic cancer, as the prevalence of hereditary syndromes only ranged from 2 to $8 \%$ among patients with pancreatic cancer below 50 years of age. ${ }^{20}$

The increased incidence of distal biliary tract malignancies in the below 30 age group relative to other periampullary primary sites may be explained by the association of congenital anomalies of the biliary tree with the development of cholangiocarcinoma later in life, reflecting the effects of chronic insult to the biliary tree. One of the cancer patients in the age group had an identified history of a choledochal cyst in childhood, highlighting the $15 \%$ risk of malignant transformation and overall risk of developing cholangiocarcinoma of up to $28 \%$ in patients with the congenital biliary cystic disease. ${ }^{7}$

Traditional knowledge of periampullary malignancies will cite the classic symptom complex of painless progressive jaundice to differentiate a neoplastic cause of biliary obstruction from the more commonly encountered biliary stone disease; however, most patients do experience some degree of pain from periampullary cancers. Pain from a pancreatic head tumor may be mild and vague, originating in the epigastric area and may have radiation to the back, and may already be present for several months before the development of other symptoms. ${ }^{14}$ 
Gastrointestinal symptoms such as nausea, vomiting, and GI bleeding had the lowest incidence in the overall study population. However, it was observed that these enteric symptoms and abdominal pain had a higher prevalence among the cases of duodenal adenocarcinoma in the study, along with lower reports of jaundice, tea-colored urine, acholic stools, and pruritus. These trends reflect the greater propensity of duodenal neoplasms to cause bowel obstruction and intraluminal bleeding rather than biliary obstruction. This was due to their origin from the duodenal mucosa and not always along the outflow tract of pancreaticobiliary secretions.

Majority of the cases where endoscopy had a positive result were from the ampullary and duodenal malignancy groups. This follows the pathophysiology of these two primary cancers as endoscopy would have a better diagnostic yield for tumors that originate within the bowel lumen. MRI and endoscopic ultrasonography had lower usage than CT and endoscopy within the entire study population, each used in less than $10 \%$ of all patients. However, in the subgroup of distal CBD tumors, these tests had higher utilization, used in almost $20 \%$ of those cases. CT scans also had lower utility in this patient group, which may be due to smaller CBD tumors not reaching the threshold of detection for the current available CT resolutions, hence the need to investigate with other modalities. These findings reiterate the use of highquality CT scans, with optimal resolution and phase studies, and upper GI endoscopy as the initial diagnostic work-up for patients with suspected periampullary malignancy. These tests have the highest diagnostic yield relatively accessible and are the most cost-effective to perform. Other modalities such as MRI, endoscopic ultrasonography, or intraoperative ultrasound assessment may be reserved for when the initial investigations are inconclusive.

Links between different comorbid conditions and environmental exposures to the development of periampullary malignancies have previously been identified in the literature. Obesity has been linked to an increased risk of developing pancreatic cancer (RR 1.72), while preexisting diabetes mellitus may predispose to pancreatic and biliary malignancies ( $R R$ of 1.97 and 1.63, respectively).,14,24,25 Genetic syndromes such as familial adenomatous polyposis, hereditary non-polyposis colon cancer, Peutz-Jeghers syndrome, and hereditary pancreatitis confer a hereditary risk to the development of all types of periampullary cancer while patients diagnosed with sporadic colon cancer are also predisposed to developing small bowel malignancies. ${ }^{6,7,15,26-28}$ Biliary disorders such as choledochal cysts and pancreaticocholedochal junction anomalies are associated with increased incidence of cholangiocarcinoma. ${ }^{7,18}$ Symptomatic gallstone disease and cholecystitis also confer additional risk for bile duct cancer, but these are still more closely linked to the development of gallbladder cancer. ${ }^{29} \mathrm{Chronic}$ inflammatory conditions of the periampullary structures, such as chronic pancreatitis, primary sclerosing cholangitis, and Crohn's disease, can also predispose to the development of pancreatic cancer, cholangiocarcinoma, and small bowel cancer, respectively. ${ }^{12,30,31}$ Tobacco use accounts for approximately $25 \%$ of cases of pancreatic cancer, with an RR of 2.5 in patients with a history of smoking, increasing with higher cigarette consumption and decreasing with smoking cessation. ${ }^{14,15,32,33}$

Recent data released from the 2019 Expanded National Nutrition Survey highlighted the rates of various lifestyle indicators in the local setting. Among Filipino adults 20 years old and above, the prevalence of an elevated BMI of $25 \mathrm{~kg} / \mathrm{m}^{2}$ and above was at $36 \%$, fasting blood sugar was elevated in $8.2 \%$ of the population, and $19.9 \%$ of adults were currently smoking at the time of the survey. ${ }^{34}$ The prevalence of gallstone disease in Asian populations is estimated at 3.1 to $10.7 \% .^{35}$

Looking at the study results, the prevalence rates of diabetes mellitus (21.32\%), smoking history (36.88\%), and biliary disease consisting mainly of cholelithiasis (19.12\%) were all noted to be higher than the nationwide and regional estimates, reflecting the possible causative relationships with periampullary malignancies. Only the prevalence of elevated BMI (17.95\%) was lower in the study population. The subgroup analysis showed a lower prevalence of elevated BMI and diabetes mellitus and a higher prevalence of smoking history in duodenal cancer patients. The former may result from duodenal tumors causing bowel obstruction with more marked effects on enteral feeding and maintenance of nutritional requirements as part of the disease process, as the weight and height measurements of the patients were taken on admission and may not reflect their premorbid status. Additional investigations may be undertaken to definitively establish a causative effect of tobacco use on the development of duodenal malignancies and confirm whether there are factual differences between younger and older age groups in the factors that influence the incidence of periampullary cancers. Larger population-based studies with case-matched controls will help determine the actual burden of these comorbid conditions towards developing these less common malignancies.

\section{CONCLUSION}

The incidence of periampullary malignancies in the local setting has shown a younger mean age at presentation by at least a decade from previously established age demographics. Equal sex distribution was noted, which refutes the malepredominated statistics from earlier studies. Nuances in the symptomatology and diagnostic modalities used for the different types of periampullary cancers have been demonstrated, which may impact their timely and accurate diagnosis. The information on other comorbid conditions as risk factors in the local population supports the disease associations identified in previous reports. However, there is still room to elucidate further specific causative relationships, 
particularly in the younger age groups, which may help better understand this infrequent but highly morbid group of cancers.

\section{Statement of Authorship}

Both authors participated in the data collection and analysis and approved the final version submitted.

\section{Author Disclosure}

Both authors declared no conflicts of interest.

\section{Funding Source}

This study was personally funded.

\section{REFERENCES}

1. Bray F, Ferlay J, Soerjomataram I, Siegel RL, Torre LA, Jemal A. Global Cancer Statistics 2018: GLOBOCAN Estimates of Incidence and Mortality Worldwide for 36 Cancers in 185 Countries. CA: A Cancer Journal for Clinicians 2018;0:1-31.

2. Siegel RL, Jakubowski CD, Fedewa SA, Davis A, Azad NS. Colorectal Cancer in the Young: Epidemiology, Prevention, Management. American Society of Clinical Oncology Educational Book 2020:40,e75-e88.

3. Sacdalan DL, Garcia RL, Diwa MH, Sacdalan DB. Clinicopathologic Factors Associated with Mismatch Repair Status Among Filipino Patients with Young-Onset Colorectal Cancer. Cancer Manag Res. 2021;13:2105-15.

4. Guo F, Kuo Y, Shih YT, Giordano SH, Berenson AB. Trends in Breast Cancer Mortality by Stage at Diagnosis among US Young Women. Cancer 2018;124(17):3500-9.

5. Del Castillo CF, Jimenez RE. Epidemiology and Nonfamilial Risk Factors for Exocrine Pancreatic Cancer. UpToDate. Waltham, MA: UpToDate Inc [Internet]. 2019 [cited 2019 July]. Available from: https://www.uptodate.com/contents/epidemiology-and-nonfamilialrisk-factors-for-exocrine-pancreatic-cancer.

6. Martin JA. Ampullary carcinoma: Epidemiology, Clinical Manifestations, Diagnosis, and Staging. UpToDate. Waltham, MA: UpToDate Inc [Internet]. 2019 [cited 2019 July]. Available from: https://www.uptodate.com/contents/ampullary-carcinomaepidemiology-clinical-manifestations-diagnosis-and-staging.

7. Lowe RC, Anderson CD. Epidemiology, Pathogenesis, and Classification of Cholangiocarcinoma. UpToDate. Waltham, MA: UpToDate Inc [Internet]. 2019 [cited 2019 July]. Available from: https://www.uptodate.com/contents/epidemiology-pathogenesis-andclassification-of-cholangiocarcinoma.

8. Overman MJ, (max of 6 authors), et al. Epidemiology, Clinical Features, and Types of Small Bowel Neoplasms. UpToDate. Waltham, MA: UpToDate Inc [Internet]. 2019 [cited 2019 July]. Available from: https://www.uptodate.com/contents/epidemiology-clinical-featuresand-types-of-small-bowel-neoplasms.

9. Yeo CJ, Sohn TA, Cameron JL, Hruban RH, Lilemoe KD, Pitt HA. Periampullary Adenocarcinoma - Analysis of 5-Year Survivors. Ann Surg 1998;227(6):821-31.

10. Hatzaras I, George N, Muscarella P, Melvin WS, Ellison EC, Bloomston M. Predictors of Survival in Periampullary Cancers Following Pancreaticoduodenectomy. Ann Surg Oncol 2010;17(4):991-7.

11. Division of Medical Oncology. 2017-2019 Annual Census. Philippine General Hospital 2019.

12. Hatzaras I, Palesty JA, Abir F, Sullivan P, Kozol RA, Dudrick SJ, et al. Small-bowel Tumors: Epidemiologic and Clinical Characteristics of 1260 Cases from the Connecticut Tumor Registry. Arch Surg 2007;142(3):229-35

13. Jarnagin WR, Allen PJ, Chapman WC, D’Angelica MI, DeMatteo RP, Kinh Gian Do R, et al. (ed). Blumgart's Surgery of the Liver, Biliary Tract, and Pancreas 6th Edition. Philadelphia, PA: Elsevier, Inc. 2017.
14. Bruncardi FC, Andersen DK, Billiar TR, Dunn DL, Hunter JG, Kao LS, et al (ed). Schwartz's Principles of Surgery 11th Edition. United States of America: McGraw-Hill Education. 2019.

15. Thapa P. Epidemiology of Pancreatic and Periampullary Cancer. Indian J Surg 2015;77(5):358-61.

16. O'Connell JB, Maggard MA, Manunga J, Tomlinson JS, Reber HA, Ko CY, et al. Survival after Resection of Ampullary Carcinoma: A National Population-based Study. Ann Surg Oncol 2008;15(7):1820-7.

17. Halfdanarson TR, McWilliams RR, Donohue JH, Quevado JF. A Single-institution Experience with 491 Cases of Small Bowel Adenocarcinoma. Am J Surg 2010;199(6):797-803.

18. Vauthey JN, Blumgart LH. Recent Advances in the Management of Cholangiocarcinomas. Semin Liver Dis 1994;14(2):109-14.

19. Raimondi S, Maisonneuve P, Lohr J, Lowenfels AB. Early Onset Pancreatic Cancer: Evidence of a Major Role for Smoking and Genetic Factors. Cancer Epidemiol Biomarkers Prev 2007;16(9):1894-1897.

20. Ntala C, Debernardi S, Feakins RM, Crnogorac-Jurcevic T. Demographic, Clinical, and Pathologic Features of Early-onset Pancreatic Cancer Patients. BMC Gastroenterology 2018;18,139.

21. Primavesi F, Stattner S, Schlick K, Kiesslich T, Mayr C, Klieser E, et al. Pancreatic Cancer in Young Adults: Changes, Challenges, and Solutions. OncoTargets and Therapy 2019;12:3387-400.

22. Alese OB, Jiang R, Shaib W, Wu C, Akce M, Gaines T, et al. Young Adults with Pancreatic Cancer: National Trends in Treatment and Outcomes. Pancreas 2020;49:341-54.

23. James TA, Sheldon DG, Rajput A, Kuvshinoff BW, Javle MM, Nava HR, et al. Risk Factors Associated with Earlier Age of Onset in Familial Pancreatic Carcinoma. Cancer 2004;101(12):2722-6.

24. Batabyal P, Hoorn SV, Christophi C, Nikfarjam M. Association of Diabetes Mellitus and Pancreatic Adenocarcinoma: A Meta-analysis of 88 Studies. Ann Surg Oncol 2014;21(7):2453-62.

25. Jing W, Jin G, Zhou X, Zhou Y, Zhang Y, Shao C, et al. Diabetes Mellitus and Increased Risk of Cholangiocarcinoma: A Meta-analysis. Eur J Cancer Prev 2012;21(1):24-31.

26. Shindo K, Yu J, Suenaga M, Fesharakizadeh S, Cho C, Macgregor-Das A, et al. Deleterious Germline Mutations in Patients with Apparently Sporadic Pancreatic Adenocarcinoma. J Clin Oncol 2017;35(30): 3382-90.

27. Pergolini I, Sahora K, Ferrone CR, Morales-Oyarvide V, Wolpin BM, Mucci LA, et al. Long-term Risk of Pancreatic Malignancy in Patients with Branch Duct Intraductal Papillary Mucinous Neoplasm in a Referral Center. Gastroenterology 2017;153(5):1284-94.

28. Scelo G, Boffetta P, Hemminki K, Pukkala E, Olsen JH, Andersen A, et al. Associations between Small Intestine Cancer and Other Primary Cancers: An International Population-based Study. Int J Cancer 2006;118(1):189-96.

29. Hsing AW, Gao YT, Han TQ, Rashid A, Sakoda LC, Wang BS, et al. Gallstones and the Risk of Biliary Tract Cancer: A Population-based Study in China. Br J Cancer 2007;97(11):1577-82.

30. Lowenfels AB, Maisonneuve P, Cavallini G, Ammann RW, Lankisch PG, Andersen JR, et al. Pancreatitis and the Risk of Pancreatic Cancer. International Pancreatitis Study Group. N Eng1 J Med 1993;328(20):1433-7.

31. Burak K, Angulo P, Pasha TM, Egan K, Petz J, Lindor KD. Incidence and Risk Factors for Cholangiocarcinoma in Primary Sclerosing Cholangitis. Am J Gastroenterol 2004;99(3):523-6.

32. Fuchs CS, Colditz GA, Stampfer MJ, Giovannucci EL, Hunter DJ, Rimm EB, et al. A Prospective Study of Cigarette Smoking and the Risk of Pancreatic Cancer. Arch Intern Med 1996;156(19):2255-60.

33. Lowenfels $\mathrm{AB}$, Maisonneuve P. Epidemiology and Risk Factors for Pancreatic Cancer. Best Pract Res Clin Gastroenterol 2006;20(2): 197-209.

34. eNutrition Nutritional Assessment and Monitoring Division. 2019 Expanded National Nutrition Survey. Food and Nutrition Research Institute, Department of Science and Technology [Internet]. 2020 [cited 2021 April]. Available from: http://enutrition.fnri.dost.gov.ph/ site/presentation. php? year $=2019$.

35. Chuang SC, Hsi E, Lee KT. Genetics of Gallstone Disease. Adv Clin Chem. 2013;60:143-85. 